\title{
Molecular-based survey of Rickettsia spp. and Coxiella burnetii in mosquitoes (Diptera: Culicidae) from Fars province, southern Iran, during 2017-18
}

\section{Zahra Hoseini}

Shiraz University of Medical Sciences

Hamzeh Alipour

Shiraz University of Medical Sciences

Kourosh Azizi

Shiraz University of Medical Sciences

Aboozar Soltani ( $\sim$ soltani_ab@sums.ac.ir)

Shiraz University of Medical Sciences https://orcid.org/0000-0003-0717-2561

Research article

Keywords: Mosquito, Rickettsia, Coxiella, molecular survey, infection, Iran

Posted Date: November 6th, 2019

DOI: https://doi.org/10.21203/rs.2.16831/v1

License: (c) (i) This work is licensed under a Creative Commons Attribution 4.0 International License.

Read Full License 


\section{Abstract}

Background Mosquito-borne diseases are main problems of public health worldwide, especially in tropical and subtropical regions. Mosquitoes can transmit human filariasis, arboviruses, malaria, and dirofilariasis. It has been recently found that Anopheles gambiae is a vector of Rickettsia felis. Both cells of Anopheles gambiae and Aedes albopictus help developing of R. felis. These studies indicated that mosquitoes could be vector of Rickettsia spp., especially R. Felis. Since there was no study on roles of the Iranian mosquitoes in transmission of Rickettsia spp. and Coxiella burnetii, the present study for the first time investigated roles of mosquitoes in the transmission of these pathogens using the PCR technique in Iran.

Methods The present study was conducted in Fars province, and mosquitoes were manually caught (hand-catch, total catch etc.) in Qir and Karzin Counties from four different geographical regions during the activity seasons of mosquitoes in 2017-18. The primers design were done to investigate the probability of mosquito's contamination with Rickettsia spp. and Coxiella burnetii from gltA genes (Rickettsia sp. citrate synthase kinase) for Rickettsia spp. and IS111 A Transposase gene for Coxiella burnetii. The conventional PCR was used after the extraction of DNA from mosquitoes to study the contamination.

Results A total of 1103 adult mosquitoes were collected and identified from four regions of the County. Among them, 3 genera and 11 species were identified including Anopheles (25.74\%) (An. dthali, An. stephensi, An. superpictus), Culex (51.84\%) (Cx pipiens, Cx sinaiticus, Cx bitaeniorhynchus, Cx theilers, Cx laticinctus, $\mathrm{Cx}$ tritaeniorhynchus, and $\mathrm{Cx}$ torrentium) and Culiseta (22.39\%) (Cu. longiareolata) genera. All tested mosquitoes were negative in terms of contamination to Rickettsia spp. and Coxiella burnetii.

Conclusions Based on the results, mosquitoes in this part of the country are not considered as vectors of Rickettsia spp. and Coxiella burnetii currently. In general, limited studies have been conducted on Rickettsial diseases in Iran and since Rickettsia spp. has been reported from different vectors in Iran and other neighboring countries, there is a need for further studies on this field in tropical areas of Iran especially in mosquitoes as a possible vector with high abundance and mobility.

\section{Background}

Mosquito-borne diseases are main public health problems worldwide, especially in tropical and subtropical regions (1-5). Despite the fact that their bite is widely annoying, they are probably the most dangerous vectors of disease or cause of mortality in humans like the past (1). Their infection issue is related to their ability to transmit various types of pathogens such as filarial nematodes, Plasmodiums, and Arboviruses. Among them, malaria, dirofilariasis, dengue fever, west nile virus (WNV), yellow fever and some other viral diseases are the most pathogenic $(1,6)$. Due to climatic conditions in tropical and subtropical regions, the invasion of mosquito, which bite the human, may be high in urban and rural places leading to the increase of mosquito-borne diseases (7). Among international travelers, malaria, 
dengue, and Rickettsial diseases are the most common causes of febrile illnesses; and the exposure to mosquitoes is reported as the most common source of fever $(2,8)$. Most vector mosquitoes, which can cause human diseases, are divided into three genera, namely Anopheles, Aedes and Culex. These genera can transmit human filariasis, arboviruses and dirofilariasis; however, only Anopheles mosquitoes can transmit five known Plasmodium parasites that cause human malaria (7). Despite a great number of research on mosquito-borne infections, there is no study on the probable transmission of Rickettsia spp. and Coxiella burnetii by mosquitoes to humans in Iran, and there are a few studies worldwide.

These are bacteria of the Rickettsiales order and are referred to as short, gram-negative and rod-shaped bacteria and need eukaryotic cells for growth and proliferation (9). In terms of history, Rickettsiales order is divided into three families namely Rickettsiaceae, Bartonellaceae and Anaplasmataceae.

Rickettsiaceae Family consists of three tribes, namely Rickettsieae, Ehrlichieae and Wolbachieae; and rickettsieae consists of three genera, namely Coxiella, Rickettsia, and Rochalimaea. Based on morphological, antigenic and metabolic characteristics, Rickettsia genus is divided into three groups: the typhus group (TG) consisting of R. typhi, R. prowazekii, and R. Canada members (10-15).

The spotted fever group (SFG) contains 20 different species of Rickettsia spp. (R. felis) $(11,13,14,16)$. The scrub typhus group includes Orientia tsutsugamushi (Rickettsia tsutsugamushi until 1995) (12-15, 17). Rickettsia spp. are transmitted through infected arthropods such as ticks, mites, fleas and lice.

Coxiella burnetii is also a gram-negative small bacterium that cannot grow in the medium $(18,19)$. This bacterium is the cause of $\mathrm{Q}$ fever disease that is common worldwide. Rickettsial diseases of Iran include endemic typhus (murine typhus) (20-24), epidemic typhus (louse-borne typhus) $(21,24,25)$ and Q fever (26-29).

In 1924, the presence of intracellular microorganisms of Rickettsia was reported in ovarian and testicle cells in Culex pipiens. (30) Later, this bacterium was introduced as Wolbachia pipientis, a member of Anaplasmataceae family in Rickettsiales order. In addition, Yen et al. introduced another type of transovarially transmitted Rickettsia through the electron microscope in 1975. (31) Therefore, we assumed that there are probably other unknown species of Rickettsia in mosquitoes. In sub-Saharan Africa, $R$. felis is the cause of $15 \%$ of the unknown fever (32). It has been recently found that Anopheles gambiae, the main vector of malaria in sub-Saharan Africa, act as a vector of $R$. felis $(2,30,31)$.

Interestingly, both cells of Anopheles gambiae and Aedes albopictus help to develop $R$. felis (7, 32-34). The research indicates that mosquitoes can play roles in transmitting Rickettsia, especially $R$. felis. Since there was no study on roles of the Iranian mosquitoes in transmitting Rickettsia and Coxiella burnetii, the present study for the first time investigated roles of mosquitoes in transmission of these pathogens using the PCR (polymerase chain reaction) technique in an endemic area of south Iran (near Persian gulf with subtropical weather). 


\section{Methods}

\subsection{Study area}

Fars Province: Fars is one of 31 provinces of Iran and is located in the south of Iran $\left(29.62^{\circ} \mathrm{N}, 52.53^{\circ} \mathrm{E}\right)$. According to topographic characters, there are three distinct climatic regions in this province. Qir and Karzin County is located in the southwest of Fars province. It is between N $28^{\circ} 32^{\prime}$ to $28^{\circ} 54^{\prime}$ latitude and $E 52^{\circ} 6^{\prime}$ to $53^{\circ} 13^{\prime}$ longitude of the Greenwich meridian ( $\left.28.48415^{\circ}, E 52.99710^{\circ}\right)$ with an area of about $98.3402 \mathrm{~km}^{2}$ based on the coupon classification in the semi-arid areas of the earth with rainy winter and hot and dry summer. The maximum temperature is $46^{\circ} \mathrm{C}$ in the summer and the minimum temperature is $25.1^{\circ} \mathrm{C}$ in the winter. The mean precipitation of this city is $270 \mathrm{~mm}$ per year. Qir and Karzin County has borders with Firuzabad, Jahrom, Khonj and Farashband counties. Sampling was carried out in four regions (including Qir, Efzar, Karzin and Emam Shahr) in the mosquito activity season every 2 months (Figure 1).

Figure 1. Map of Qir and Karzin County and sampling locations

\subsection{Mosquitoes collecting and identifying}

Mosquitoes were collected by hand-catch, total catch from indoor and outdoor places (human and animal) $(7,35,36)$. All needed data like date, location and hour of collecting were recorded along with mosquito species. Adult specimens of mosquitoes were pinned and kept at the Museum of Medical Entomology (Shiraz University of Medical Sciences, Department of Medical Entomology). In this study another innovative and effective method was used for catching mosquitos. In this method, wasted tires were placed in the target places and filled with water to attract mosquitoes for resting to these moist environments. Two to three days after using tires, they were covered with nets with small pores, and shake them, so that mosquitoes, which were resting flied upwards and got caught by the net. The aspirator was then inserted slowly from the corner of net and mosquitoes were collected and transported into the cups. The caught mosquitoes were transferred alive to the Medical Entomology Laboratory of Shiraz University of Medical Sciences for further studies. After pinning, the mosquitoes were identified using a valid identification key (37).

Adult mosquitoes were collected by simple random sampling. Since there was no research on this field, and the prevalence was not known in Iran, sample size was calculated according to the statistical consultant's opinion based on similar studies using the sample size formula; and 600 mosquitoes were necessary for this project. For this study, about 1103 specimens were caught and then Anophelinae and Culicinae mosquitoes were identified using valid identification keys $(37,38)$. Molecular tests were performed on both Anophelinae and Culicinae mosquitoes. 


\subsection{Molecular experiments}

\subsubsection{Designing primer for gene identification of Rickettsia spp. and Coxiella burnetii}

The primers were designed to identify Rickettsia spp. and Coxiella burnetii in mosquitoes. Therefore, the DNA sequences of Coxiella burnetii (MH920311.1 and CP018150.1) and various Rickettsia species (CP002912.1, CP002912.1, CP002912.1 and MG906669.1) were obtained from the NCBI website; and the alignment was done using Mega6 software, and then the primer was designed based on Conserve points using Oligo7.0 and Generunner4.0 software according to gltA (Rickettsia spp. citrate synthase kinase) and IS111 A Transposase genes to identify Rickettsia and Coxiella burnetii species (Table 1).

Table 1. Designed primers for identification of Rickettsia spp. and Coxiella burnetii

\begin{tabular}{llll}
$\begin{array}{l}\text { Expected } \\
\text { size }\end{array}$ & $\left(5^{\prime} \_3^{\prime}\right)$ Primer sequence & $\begin{array}{l}\text { Primer } \\
\text { name }\end{array}$ & Gen \\
\hline 828 bp & $\begin{array}{l}\text { TCT CAT CCT ATG GCT ATT } \\
\text { ATG C }\end{array}$ & GIt F & $\begin{array}{l}\text { g/tA (Rickettsia spp. citrate synthase } \\
\text { kinase) }\end{array}$ \\
\hline
\end{tabular}

Glt R

CTT CGT GCA TTT CTT TCC ATT

$813 \mathrm{bp}$

TAT GTA TCC ACC GTA GCC

Cox F

IS111 A Transposase gene AGT C

CCA ACA ACA CCT CCT TAT

Cox R

TCC C

\subsubsection{DNA extraction from mosquitoes}

After identification of mosquitoes in the present study, the DNA extraction was performed using Gene all kit (cat.No. 106-101 South Korea). Procedures of this method were carried out in accordance with the manufacturer's instructions. Due to small sizes of mosquitoes, about 20 mosquitoes of the same genera and species were extracted for each time (pooled). Concentrations of prepared DNA were measured using the NanoDrop machine; and necessary amounts (100-200ng) for each of them were calculated to enter the PCR. 


\subsubsection{Conventional PCR}

Materials with listed concentrations in Table 2 with a final volume of $20 \mu l$ were used do the conventional PCR.

Table 2. Materials and concentrations used in conventional PCR

\begin{tabular}{lll} 
Final concentration & Amount & PCR mix component \\
\hline $1 \mathrm{X}$ & $2 \mu \mathrm{l}$ & PCR buffer 10X \\
\hline $400 \mathrm{nM}$ & $1.0 \mu \mathrm{l}$ & Forward primer \\
\hline $400 \mathrm{nM}$ & $1.0 \mu \mathrm{l}$ & Reverse primer \\
\hline $1.5 \mathrm{mM}$ & $0.75 \mu \mathrm{l}$ & $\mathrm{Mg} \mathrm{Cl}_{2}(50 \mathrm{mM})$ \\
\hline $1 \mathrm{unit}$ & $0.2 \mu \mathrm{l}$ & Taq DNA polymerase $^{-2}$ \\
\hline $0.2 \mathrm{mM}$ & $0.5 \mu \mathrm{l}$ & $\mathrm{dNTPs}(10 \mathrm{mM})$ \\
\hline $100-200 \mathrm{ng} /$ reaction & Variable & DNA \\
\hline- & adjust to $20 \mu \mathrm{l}$ & Water(DDW)
\end{tabular}

Variables of conventional PCR during the research were obtained from using specific forward and reverse primers of gene as well as the PCR at the specific binding temperature(Annealing) relating to the same primers. All PCRs were done using the Analytikjena machine made in Germany. The following program was used to do the conventional PCR (Table 3).

Table 3. Thermocycling programe for PCR assay 


\begin{tabular}{llllll}
$\begin{array}{l}\text { Final } \\
\text { extension }\end{array}$ & Extension & Annealing & Denaturation & $\begin{array}{l}\text { Initial } \\
\text { denaturation }\end{array}$ & Stages \\
\hline $72{ }^{\circ} \mathrm{C}$ & $72{ }^{\circ} \mathrm{C}$ & $\begin{array}{l}54^{\circ} \mathrm{C} \mathrm{Glt} \\
50^{\circ} \mathrm{C} \mathrm{Cox}\end{array}$ & $94^{\circ} \mathrm{C}$ & $94^{\circ} \mathrm{C}$ & Temperature \\
\hline $10 \mathrm{~min}$ & $\begin{array}{l}60 \\
\text { seconds }\end{array}$ & $\begin{array}{l}30 \\
\text { seconds }\end{array}$ & 30 seconds & 5 seconds & Time \\
\hline 1 cycle & & 35 Cycle & & 1 cycle & $\begin{array}{l}\text { Number of } \\
\text { cycles }\end{array}$ \\
\hline
\end{tabular}

The present study used ready tubes of Taq DNA Polymerase 2x Master Mix RED of Amplicon Cat. No.: A190303 (Taq 2x master mix, red, and 1.5mM mgch2) for doing the PCR. The tubes had all necessary materials to do the PCR including Buffer 10X, MgCl2, dNTPs and Taq DNA polymerase solution; and specific primers, Template DNAand adjust the volume to $20 \mu \mathrm{l}$ by adding double-distilled water (DDW) water. To do the test, $1 \mu \mathrm{l}$ of DNA template (at a concentration of 100 to $200 \mathrm{ng} / \mu \mathrm{l}$ ), $12.5 \mu \mathrm{l}$ of master mix, $1 \mu$ of both primers, and DDW for adjust up to $20 \mu$ entered the microtube 0.2 then the materials were slowly pipetted and then a small Spin was done. The 0.2 microtube was put in the thermal cycler device and the schedule was given to the device. After the required time and the device turned-off, PCR product was run on the $1 \%$ gel agarose, the electrophoresis tank was adjusted to a voltage of 100 volts. After 1 hour, the gel was put in the Gel Documentation System to see DNA bands and the attached monitor to the system showed sizes of bands by turning on the UV button $(34,39,40)$.

Positive control of Coxiella burnetii and Rickettsia spp. were prepared from Pasteur Institute of Iran (IPI) and used for molecular assay.

\section{Results}

\subsection{Entomological study}

In the present study, a total of 1103 adult culicidae mosquitoes were collected and identified from four regions of Qir and Karzin County including Qir, Efzar, Emam Shahr, and Karzin during the activity seasons of mosquitoes (spring, summer and autumn of 2017-18). Among them, 3 genera and 11 species were identified including Anopheles (25.74\%) (An. dthali, An. stephensi, An. superpictus), Culex (51.84\%) (CX pipiens, $C x$ sinaiticus, $C x$ bitaeniorhynchus, $C x$ theilers, $C x$ laticinctus, $C x$ tritaeniorhynchus, and $C x$ torrentium) and Culiseta (22.39\%) (Cu. longiareolata) genera (Table 4). 
Table 4. Frequency of mosquito species collected from different sampling regions from Qir and Karzin County, southern Iran, 2017-18

\begin{tabular}{|c|c|c|c|c|c|c|c|}
\hline \multirow[t]{2}{*}{ Genus } & \multirow[t]{2}{*}{ Species } & \multicolumn{4}{|c|}{ Sampling locations } & \multirow{2}{*}{$\begin{array}{l}\text { No. of } \\
\text { collected } \\
\text { samples }\end{array}$} & \multirow{2}{*}{$\begin{array}{l}\text { Percentage } \\
\text { (\%) }\end{array}$} \\
\hline & & Qir & Efzar & Karzin & $\begin{array}{l}\text { Emam } \\
\text { Shahr }\end{array}$ & & \\
\hline \multirow[t]{5}{*}{ Culex } & Cx. pipiens & 69 & 26 & 17 & 25 & 137 & 12.42 \\
\hline & Cx. sinaiticus & 55 & 220 & 30 & 102 & 407 & 36.90 \\
\hline & $\begin{array}{l}\text { Cx. } \\
\text { bitaeniorhynchus }\end{array}$ & 0 & 3 & 0 & 0 & 3 & 0.27 \\
\hline & $C x$. theileri & 5 & 11 & 0 & 0 & 16 & 1.45 \\
\hline & Cx. laticinctus & 3 & 6 & 0 & 0 & 9 & 0.82 \\
\hline \multirow[t]{3}{*}{ Anopheles } & An. stephensi & 22 & 28 & 33 & 41 & 124 & 11.24 \\
\hline & An.dthali & 58 & 52 & 15 & 29 & 154 & 13.96 \\
\hline & An. superpictus & 0 & 3 & 0 & 3 & 6 & 0.54 \\
\hline \multirow[t]{2}{*}{ Culiseta } & Cu. longiareolata & 123 & 55 & 38 & 31 & 247 & 22.39 \\
\hline & Total & 335 & 404 & 133 & 231 & 1103 & 100 \\
\hline
\end{tabular}

\section{2-3-The possible contamination of adult mosquitoes with Rickettsia sp. and Coxiella burnetii}

The collected adult mosquitoes in this county were examined in terms of possible contamination with Rickettsia spp. and Coxiella burnetii using the conventional PCR in the medical entomological lab of Faculty of Health at Shiraz University of Medical Sciences. After doing molecular assays, samples were all negative for Rickettsia spp. and Coxiella burnetii (Figure 2). Positive control of Coxiella burnetii and Rickettsia spp. were detected in this assay with the same procedure (Figure 3).

Figure 2. A gel scheme and the negative result of testing the possible contamination of mosquitoes with Rickettsia spp. and Coxiella burnetii (from left to right: 1: Negative control:; 2,3 and4:: examined samples in terms of gltA; 5 and 6: examined samples in terms of Coxiella burnetii), and 7: Ladder 100bp sinaclone Co.

Figure 3. A gel scheme of positive control of Coxiella burnetii and Rickettsia spp.

\section{Discussion}


In general, there are few studies on Rickettsial diseases in Iran. A study was recently conducted by Ghavami et al. who investigated an ITS1 part of gltA gene and Rickettsia contamination in human flea (Pulex irritans) in Iran. Their results indicated that $4.9 \%$ out of 182 samples of human flea were contaminated with Rickettsia sp. (41). Azizi et al. conducted an overview of epidemic Typhus in the world in the 19th and 20th centuries and stated that typhus was a major Rickettsial disease in Iran (24). Historically, typhus (Rickettsial disease) was a major health problem with an economic impact on Iran; however, there is limited published information on the prevalence of typhus over the centuries. Typhus has been an endemic disease in Iran, but its prevalence has been rare. In the Qajar period (1796-1925), infectious diseases including typhus were common. In the twentieth century, the prevalence of typhus occurred in Iran (24).

Spotted Fever Group (SFG) Rickettsioses occur worldwide and may cause serious illnesses in humans. They are transmitted to humans by vector arthropods such as ticks, fleas and lice (42-47). In the Middle East, a number of known species of Rickettsia genus have been reported, but some studies are suspicious (48). Al-Deeb et al. reported the first case of spotted fever group of Rickettsia sp. and Theileria annulata in Hyalomma dromedarii tick that was collected from camels in the United Arab Emirates (49). Furthermore, Rickettsia sibrica mongolitimonae was diagnosed in a male patient in Turkey in 2016 (50). Mediterranean Spotted Fever (MSF) is caused by Rickettsia conorii subsp. Israelensis as a main cause of fever and chills from spotted fever group rickettsiosis in collected ticks from mice, deers, goats, red foxes and wild boars $(48,51)$.

According to conducted studies in the Middle East, the presence of different types of ticks, which can transmit Rickettsia in several countries including Yemen, Saudi Arabia, and Oman throughout the Middle East, can cause Rickettsial diseases in the Middle East $(48,52,53)$. Despite the evidence of presence of Rickettsial SFG pathogens in the Middle East, there is no study on this disease in Iran. Therefore, it is necessary to study the SFG Rickettsiae to better understand the epidemiology of this disease in Iran (48). There is only a paper on the spotted-fever group rickettsioses and it investigates 40 samples of human serum collected from 4 countries including Iran for the presence of spotted fever group rickettsia antibodies among other pathogens by Kovacova et al. From 40 human laboratory samples, $45 \%$ were positive in terms of SFG rickettsia by the ELISA test, and $27.5 \%$ were positive using the IFA test $(48,54)$.

Idris et al. studies 347 human serum samples for Rickettsia infections in Dhofar, Oman, and their results indicated that $59 \%$ of samples were positive. (55).

Studies indicate that there are different genera of the Rickettsia order including Coxiella, Anaplasma, Ehrlichia, and Wolbachia in different arthropods in Iran. Coxiellosis, erlichiosis, anaplasmosis and SFG rickettsioses, which are zoonotic, increase the presence of its agents in the environment and the risk of human-animal transmission. The insufficient information about SFG Rickettsioses in Iran indicates the absence of pathogens in the population. However, there is a need for studies on the SFG Rickettsioses among a wide range of organisms across the country as it is difficult to determine the range of hosting, 
the zoonotic potential and actual prevalence of SFG Rickettsioses in Iran. Several studies indicate the presence of Rickettsia species in Iran; some of them are as follows:

Spitalska et al. (2004) examined tick-borne diseases in small domestic ruminants in Iran. Collected ticks were infected with Ehrlichia ovina, Theileria lestoquardi and Theileria spp. (56).

Jalali et al. (2013) investigated the Anaplasma infection in blood samples of sheep in Ahvaz by the PCRRLFP method. In $80 \%$ of samples, there was an infection caused by $A$. ovis and A. marginale (57). Noaman et al. (2017) conducted an overview of Anaplasmosis in the Iranian ruminants (58).

Yousefi et al. (2017) investigated the molecular evidence of presence of Anaplasma phagocytophilum as a tick-borne pathogen in small domestic ruminants in Iran. $1 \%$ of blood samples were positive. The research was the first report of this pathogen in Iran (59). Parvizi et al., (2013) isolated Wolbachia pipientis from Phlebotomus kandelakii and Phlebotomus perfiliewi sandflies (60). Karimian F., et al., (2018) studied wsp-based analysis of Wolbachia strains associated with Phlebotomus papatasi and $P$. sergenti (Diptera: Psychodidae) main cutaneous leishmaniasis vectors, introduction of a new subgroup wSerg (61).

Q fever is caused by a small and intercellular gram-negative bacterium, called Coxiella burnetii. Domestic ruminants including cow, sheep and goats, are considered as main reservoirs of $C$. burnetii to cause a human infection. Infected ticks can play important roles in the transmission of bacteria among mammals, rodents and other mammals as well as wild and domestic birds. Q fever is domestic in Iran $(23,29,62)$. It has been reported that rodents have been infected by named infectious agent in Iran during the 1970s; however, there has been no report of rodent infections and transmission to humans in recent decades (62). There are many reports about the infection of other animals and their products with $C$. burnetii in different provinces of Iran like Fars, Khuzestan, Yazd, Chaharmahal and Bakhtiari, Isfahan, Gilan and Mazandaran $(23,26,27,29)$.

In a research by Rahimi in 2010, he investigated the prevalence of $C$. burnetii in cow's milk samples from dairy cattle of Fars, Kerman, Qom, Yazd and Khuzestan provinces. 18\% of collected samples from Fars were infected (27).

In a study by Doosti et al. in 2014, they studied the prevalence of $C$. burnetii in camels of Iran. In this study, blood samples were taken from 130 camels; and the PCR method was used for their study. $10 \%$ of samples were positive (63).

A research was conducted by Parhizgari et al. in 2017 and they reviewed Emerging and re-emerging infectious diseases in Iran and declared that $Q$ fever was an endemic disease caused by $C$. burnetii in Iran (64) .

Rahmdel et al. (2018) investigated C. Burnetii in cow's milk samples in Shiraz (capital of Fars province) using the PCR method. Their results indicated that $3 \%$ of milk samples were contaminated, and cows' raw milk could be a potential source of $C$. burnetii in Shiraz in the southern Iran (65). Ghavami et al. (2018) 
investigated ITS1 and Rickettsia infection rate in human fleas (Pulex irritans). Their results indicated that $4.9 \%$ of 182 samples of human fleas were infected with Rickettsia spp. (41). Traub et al. (1974) studied the ecology of scrub typhus. In their study, they predicted that the infection could be present in northern regions of Iran despite no evidence of infection (66).

In recent years, studies have indicated that mosquitoes can be potential vectors for Rickettsiae. According to studies, the importance of presence of mosquitoes has multiplied in regions where there are many vector-borne diseases; and mosquitoes can be also considered as vectors of Rickettsiae. Some studies on the potential of mosquitoes for transmitting Rickettsial diseases are as follows:

Among the first studies on the presence of Rickettsiae in mosquitoes, a research reported the presence of intracellular microorganisms of Rickettsia in ovarian and testicle cells of Culex pipiens mosquito in 1924 (30). Later, this bacterium was known as Wolbachia pipientis, a member of Anaplasmataceae family in Rickettsiales order. In addition, Yen introduced another type of transovarially transmitted Rickettsia using the electron microscopy in 1975 (31).

In 2006, Horta et al. could develop R. Felis in the c6/36 cell of Aedes albopictus mosquito. Their results indicated that mosquito cells could be used to cultivate this rickettsia. In the study, 90 to $100 \%$ of cells were infected after adding pathogen to these cells after 15 days of incubation at $25^{\circ} \mathrm{C}(33)$.

In a similar study in 2007, they examined the proliferation of transmitted Rickettsiae by arthropods in two types of mosquito cells. In this study, they used two cells, Aedes albopictus Aa23 and Anopheles gambiae Sua5B. They proliferated three species, namely Rickettsia felis, $R$. montanensis and $R$. peacockii in the cells. They found that the cells were also suitable for the cultivation of difficult - cultivable Rickettsiae such as R. peacockii (67).

Another study in 2011, examined the impact of Wolbachia on Culex quinquefasciatus. It was found that this kind of Rickettsia affected the ovary and reproduction of mosquito. The infected females are laying eggs before the usual time, and the eggs spend more time than healthy eggs. Healthy females produce more eggs than infected ones (68).

In a study in 2011, the $R$. Felis infection was investigated as a pathogen that was transmitted by mosquitoes in the future. They argued that due to the separation of this Rickettsia from people with fever in tropical regions, where there were numerous Ae.albopictus and Ae.aegypti mosquitoes and they easily bit people, Aedes spp. mosquitoes could spread the infection in the future (32). In a study in the same year, they investigated the role of Wolbachia in controlling mosquito-borne diseases. The results indicated that Fruit fly Wolbachia strains could infect mosquitoes and affected the longevity, reproduction and pathogen entry to the mosquito's body (69).

A research in 2012 provided an examination of Rickettsia species in Anopheles of Africa. The real-time PCR and conventional PCR method were used by sequencing gltA, ompB, ompA and sca4 genes. DNA of Rickettsia was not separated from An.arabiensis, An.funestus and An.gambiae (molecular form M). R. 
felis was separated from An.gambiae molecular form S as the most important vector of malaria in Africa (7).

In a study in 2015, the researchers investigated a potential transmission of R.felis by An.gambiae mosquito. In this test, An.gambiae were infected with Rickettsia in the laboratory, and the infected mosquitoes were exposed to balb/c rats. The results indicated that the mosquitoes were able to transmit $R$. felis to rats; hence, mosquitoes could be potential vectors of this Rickettsia (70).

In another study in 2017, the researchers examined molecular characteristics of the species of mosquitoborne Rickettsiae in collected sample mosquitoes from a Korean civilian region. In this study, Rickettsiae were detected using real-time PCR and sequencing rss, $g / t A, 17 \mathrm{kDa}$, ompB, and sca4 genes. Three new Rickettsia genotypes were detected from Mansonia uniformis, Culex pipiens, and Aedes esoensis (71).

In a research in Africa in 2017, a new species of Wolbachia was detected in malaria vectors. They could isolate this bacterium from 5 Anopheles species (72).

In one of the latest studies in this field in 2019, the researchers studied $R$. felis in mosquitoes in China. They investigated three species including Culex pipiens, C. tritaeniorhynchus, and Aedes albopictus in terms of Rickettsia; and all three species were positive (73).

\section{Conclusion}

All these studies indicate the higher importance of mosquitoes in regions where there are Rickettsia infections. There are few studies on the presence of Rickettsial diseases in Iran.

According to the results of this study, mosquitoes in this part of the country are not considered as vectors of Rickettsia spp. and Coxiella burnetii currently. We can attribute the negative outcomes to several main factors, such as the inability of mosquitoes to support pathogens in order to establish, grow and replication within their bodies and having different geographic conditions.

In general, limited studies have been conducted on Rickettsial diseases in Iran and since Rickettsia spp. has been reported from different vectors in Iran and other neighboring countries, there is a need for further studies on this field in tropical areas of Iran especially in mosquitoes as a possible vector with high abundance and mobility.

Given the fact that there are numerous travels to different regions of the world with Rickettsia infection such as Southeast Asia, and Middle Eastern countries; and people enter Iran from neighboring countries such as Pakistan with the possibility of infection, there is a need for more comprehensive and accurate study on this field, especially in Southern provinces of Iran such as Sistan and Baluchestan, Fars, khozestan, Bushehr, and Hormozgan.

Rickettsial disease should be considered important and travelers, who are returning from neighboring countries especially Saudi Arabia travelers for Hajj ritual with symptoms of fever and headache, should 
be screened. The importance of these diseases and their causes should be taken seriously into consideration before they create serious problems for the society.

It is suggested that a comprehensive study at a wider level should be done in other endemic areas of Iran in order to define the prevalence of Rickettsial infection rate in mosquitoes. In this case, we will be able to understand the exact role of mosquitoes in the cycle of transmission of these pathogens to humans in Iran.

\section{Declarations}

\section{Acknowledgements}

Authors are thankful to the assistance of vice-chancellorship for research and technology at Shiraz University of Medical Sciences (SUMS). This paper has partly been derived from, and supported by Ms. Zahra Hoseini Master of Science thesis (Grant No: 1396-01-04-16676) in Medical Entomology, at School of Health, SUMS.

\section{Ethics approval and consent to participate}

Not applicable

\section{Consent for publication}

Not applicable

\section{Availability of data and material}

All data are available

\section{Competing interests}

No conflict or competing financial interests exists.

\section{Funding}

Not applicable

\section{Authors' contributions}

$\mathrm{ZH}$ and $\mathrm{AB}$; Designed and performed experiments, analyzed data and co-wrote the paper. $\mathrm{ZH}, \mathbf{A B}, \mathrm{KA}$, and HA; Performed experiments and co-wrote the paper. AB, KA, and HA; Supervised the research. 


\section{References}

1. Abai MR, Hanafi-Bojd AA, Vatandoost H. Laboratory evaluation of temephos against Anopheles stephensi and Culex pipiens Larvae in Iran. Journal of arthropod-borne diseases. 2016;10(4):510.

2. Mediannikov O, Socolovschi C, Edouard S, Fenollar F, Mouffok N, Bassene H, et al. Common epidemiology of Rickettsia felis infection and malaria, Africa. Emerging infectious diseases. 2013;19(11):1775.

3. Alipour $\mathrm{H}$, Ladonni H, Abai M, Moemenbellah-Fard M, Fakoorziba M. Laboratory efficacy tests of pyrethroid-treated bed nets on the malaria vector mosquito, Anopheles stephensi, in a baited excitorepellency chamber. Pakistan J Biol Sciences. 2006;9(10):1877-83.

4. Alipour H, Amiri SA, Delavari A, Amiri A. Epidemiology of malaria in Nikshahr, Sistan and Baluchestan province, Southeast Iran, during 2004-2010. Annals of Tropical Medicine and Public Health. 2013;6(4):430.

5. Hoosh-Deghati H, Dinparast-Djadid N, Moin-Vaziri V, Atta H, Raz AA, Seyyed-Tabaei SJ, et al. Composition of anopheles species collected from selected Malarious areas of Afghanistan and Iran. Journal of arthropod-borne diseases. 2017;11(3):354.

6. Yaser SA, Hassan V, Yavar R, Reza AM, Reza SDA, Azim P. Evaluation of biological control agents for mosquitoes control in artificial breeding places. Asian Pacific Journal of Tropical Medicine. 2010;3(4):276-7.

7. Socolovschi C, Pages F, Ndiath MO, Ratmanov P, Raoult D. Rickettsia species in African Anopheles PLoS One. 2012;7(10):e48254.

8. Wilson ME, Weld LH, Boggild A, Keystone JS, Kain KC, Von Sonnenburg F, et al. Fever in returned travelers: results from the GeoSentinel Surveillance Network. Clinical infectious diseases. 2007;44(12):1560-8.

9. Shpynov S, Fournier P-E, Pozdnichenko N, Gumenuk A, Skiba A. New approaches in the systematics of rickettsiae. New microbes and new infections. 2018;23:93-102.

10. Richards AL, Jiang J, Omulo S, Dare R, Abdirahman K, Ali A, et al. Human infection with Rickettsia felis, Kenya. Emerging infectious diseases. 2010;16(7):1081.

11. Sekeyova Z, Roux V, Raoult Phylogeny of Rickettsia spp. inferred by comparing sequences of'gene D', which encodes an intracytoplasmic protein. International journal of systematic and evolutionary microbiology. 2001;51(4):1353-60.

12. Roux V, Raoult D. Phylogenetic analysis of the genus Rickettsia by $16 S$ rDNA sequencing. Research in Microbiology. 1995;146(5):385-96.

13. Horta MC, Labruna MB, Pinter A, Linardi PM, Schumaker TT. Rickettsia infection in five areas of the state of São Paulo, Brazil. Memórias do Instituto Oswaldo Cruz. 2007;102(7):793-801.

14. Azad AF, Beard CB. Rickettsial pathogens and their arthropod vectors. Emerging infectious diseases. 1998;4(2):179. 
15. Raoult D, Roux V. Rickettsioses as paradigms of new or emerging infectious diseases. Clinical Microbiology Reviews. 1997;10(4):694-719.

16. Elfving K, Olsen B, Bergström S, Waldenström J, Lundkvist Å, Sjöstedt A, et al. Dissemination of spotted fever rickettsia agents in Europe by migrating birds. PLoS One. 2010;5(1):e8572.

17. Satjanadumrong J, Robinson MT, Hughes T, Blacksell SD. Distribution and Ecological Drivers of Spotted Fever Group Rickettsia in Asia. EcoHealth. 2019:1-16.

18. Van den Brom R, Van Engelen E, Roest H, Van der Hoek W, Vellema P. Coxiella burnetii infections in sheep or goats: an opinionated Veterinary microbiology. 2015;181(1-2):119-29.

19. Angelakis E, Raoult D. Q fever. Veterinary microbiology. 2010;140(3-4):297-309.

20. Bitam I, Dittmar K, Parola P, Whiting MF, Raoult D. Fleas and flea-borne diseases. International journal of infectious diseases. 2010;14(8):e667-e76.

21. Van Rooyen C, Bowie J, Krikorian K. Typhus research in Egypt, Palestine, Iraq and Iran. Transactions of the Royal Society of Tropical Medicine and Hygiene. 1944;38(2):133-49.

22. Darvishi MM, Youssefi MR, Changizi E, Lima RR, Rahimi MT. A new flea from Iran. Asian Pacific journal of tropical disease. 2014;4(2):85-7.

23. Kazemi-Moghaddam V, Dehghani R, Hadei M, Dehqan S, Sedaghat MM, Latifi M, et al. Rodent-borne and rodent-related diseases in Iran. Comparative Clinical Pathology. 2018:1-13.

24. Azizi MH, Moslem Bahadori M. An Overview of Epidemic Typhus in the World and Iran during the 19th and 20th Centuries. Archives of Iranian medicine. 2016;19(10):751.

25. Bodman RI, Stewart IS. Louse-borne relapsing fever in British Medical Journal. 1948;1(4545):291.

26. Khalili M, Sakhaee E. An update on a serologic survey of Q Fever in domestic animals in Iran. Am J Trop Med Hyg. 2009;80(6):1031-2.

27. Rahimi E. Coxiella burnetii in goat bulk milk samples in Iran. African Journal of Microbiology Research. 2010;4(21):2324-6.

28. Ghalyanchi Langeroudi A, Babkhani N, Zolfaghari MR, Majidzadeh Arbadili K, Morovvati A, Soleimani M. Detection of Coxeilla brunetii in bulk tank milk samples from dairy bovine farms using nestedPCR in Qom, Iran, 2011. Iranian Journal of Veterinary Medicine. 2013;7(3):207-11.

29. Nokhodian Z, Feizi A, Ataei B, Ghaffari Hoseini S, Mostafavi E. Epidemiology of Q fever in Iran: A systematic review and meta? analysis for estimating serological and molecular prevalence. 2017. 2017.

30. Hertig M, Wolbach SB. Studies on rickettsia-like micro-organisms in insects. The Journal of medical research. 1924;44(3):329.

31. Yen JH. Transovarial transmission of rickettsia-like microorganisms in mosquitoes. Annals of the New York Academy of Sciences. 1975;266(1):152-61.

32. Parola P, Musso D, Raoult D. Rickettsia felis: the next mosquito-borne outbreak? The Lancet Infectious Diseases. 2016;16(10):1112-3. 
33. Horta MC, Labruna MB, Durigon EL, Schumaker TT. Isolation of Rickettsia felis in the mosquito cell line C6/36. Applied and environmental microbiology. 2006;72(2):1705-7.

34. Socolovschi C, Pagés F, Raoult D. Rickettsia felis in Aedes albopictus mosquitoes, Libreville, Gabon. Emerging infectious diseases. 2012;18(10):1687.

35. Orlandi-Pradines E, Rogier C, Koffı B, Jarjaval F, Bell M, Machault V, et al. Major variations in malaria exposure of travellers in rural areas: an entomological cohort study in western Cote d'Ivoire. Malaria journal. 2009;8(1):171.

36. Machault V, Gadiaga L, Vignolles C, Jarjaval F, Bouzid S, Sokhna C, et al. Highly focused anopheline breeding sites and malaria transmission in Dakar. Malaria Journal. 2009;8(1):138.

37. Azari-Hamidian S, Harbach RE. Keys to the adult females and fourth-instar larvae of the mosquitoes of Iran (Diptera: Culicidae). Zootaxa. 2009;2078(1):1-33.

38. Shahgudian ER. A key to the anophelines of Iran. Acta Medica Iranica. 1960:38-48.

39. Zhang J, Kelly PJ, Lu G, Cruz-Martinez L, Wang C. Rickettsia in mosquitoes, Yangzhou, China. Emerging microbes \& infections. 2016;5(10):e108.

40. Socolovschi C, Ahuka-Mundeke S, Ratmanov P, Butel C, Ayouba A, Inogwabini B-I, et al. Molecular evidence for the presence of Rickettsia felis in the feces of wild-living African apes. PLoS One. 2013;8(2):e54679.

41. Ghavami MB, Mirzadeh H, Mohammadi J, Fazaeli A. Molecular survey of ITS1 spacer and Rickettsia infection in human flea, Pulex irritans. Parasitology research. 2018;117(5):1433-42.

42. Brouqui P, Parola P, Fournier PE, Raoult D. Spotted fever rickettsioses in southern and eastern Europe. FEMS Immunology \& Medical Microbiology. 2007;49(1):2-12.

43. Uchida T, Uchiyama T, Kumano K, Walker DH. Rickettsia japonica sp., the etiological agent of spotted fever group rickettsiosis in Japan. International journal of systematic bacteriology. 1992;42(2):303-5.

44. Unsworth N, Stenos J, R Graves S, Faa A, Erika Cox G, R Dyer J, et al. Flinders Island Spotted Fever Rickettsioses Caused by "marmionii" Strain of Rickettsia honei, Eastern Australia2007. 566-73 p.

45. Rutherford JS, Macaluso KR, Smith N, Zaki SR, Paddock CD, Davis J, et al. Fatal spotted fever rickettsiosis, Kenya. Emerg Infect Dis. 2004;10(5):910-3.

46. Raoult D. A new rickettsial disease in the United States. Clinical infectious diseases : an official publication of the Infectious Diseases Society of America. 2004;38(6):812-3.

47. http://www.cdc., gov/ehrlichiosis/. Centers for Disease Control and Prevention. Ehrlichiosis. CDC. 2016. Available at Accessed 12 Mar 2018 [

48. Khamesipour F, Dida GO, Anyona DN, Razavi SM, Rakhshandehroo E. Tick-borne zoonoses in the Order Rickettsiales and Legionellales in Iran: A systematic review. PLoS neglected tropical diseases. 2018;12(9):e0006722.

49. Al-Deeb MA, Muzaffar SB, Abu-Zeid YA, Enan MR, Karim S. First record of a spotted fever group Rickettsia sp. and Theileria annulata in Hyalomma dromedarii (Acari: Ixodidae) ticks in the United Arab Emirates. Florida entomologist. 2015;98(1):135-9. 
50. Kuscu F, Orkun O, Ulu A, Kurtaran B, Komur S, Inal AS, et al. Rickettsia sibirica mongolitimonae infection, Turkey, 2016. Emerging infectious diseases. 2017;23(7):1214.

51. Mumcuoglu KY KA, Gilead L. Mediterranean spotted fever in Israel: a tick-borne disease. Med Assoc J. 2002;4(1):44-9.

52. Pegram RG HH, Wassef HY. Ticks (Acari: Ixodoidea) of the Yemen Arab Republic. I. Species infesting livestock. Bull Entomol Res. 1982;72:215-27.

53. Hoogstraal H. Ticks (Ixodoidea) from Oman. Journal of Oman Studies. 1980;2:265-72.

54. Kovacova E SW, Stunzner D, Urvolgyi J. Kazar J. Serological examination of human and animal sera from six countries of three continents for presence of rickettsial antibodies. Eur J Epidemiol. 1996;12:85-9.

55. Idris M, Ruppel A, Petney T. Antibodies against rickettsia in humans and potential vector ticks from Dhofar, Oman. Journal for scientific research Medical sciences/Sultan Qaboos University. 2000;2(1):7.

56. Spitalska E, Namavari MM, Hosseini MH, Shad-del F, Amrabadi OR, Sparagano OA. Molecular surveillance of tick-borne diseases in Iranian small ruminants. Small Ruminant Research. 2005;57(23):245-8.

57. Jalali S, Khaki Z, Kazemi B, Bandehpour M, Rahbari S, RAZIJALALI M, et al. Molecular detection and identification of Anaplasma species in sheep from Ahvaz, Iran. 2013.

58. Noaman V, Allameh SK, Nabavi R. Anaplasmosis in Ruminants of Iran: An Overview. Advanced Techniques in Clinical Microbiology. 2017;1(2).

59. Yousefi A, Rahbari S, Shayan P, Sadeghi-dehkordi Z, Bahonar A. Molecular evidence of Anaplasma phagocytophilum: an emerging tick-borne pathogen in domesticated small ruminant of Iran; first report. Comparative Clinical Pathology. 2017;26(3):637-42.

60. Parvizi P, Fardid F, Soleimani S. Detection of a new strain of Wolbachia pipientis in Phlebotomus perfiliewi transcaucasicus, a potential vector of visceral Leishmaniasis in north west of Iran, by targeting the major surface protein gene. Journal of arthropod-borne diseases. 2013;7(1):46.

61. Karimian F, Vatandoost H, Rassi Y, Maleki-Ravasan N, Choubdar N, Koosha M, et al. wsp-based analysis of Wolbachia strains associated with Phlebotomus papatasi and sergenti (Diptera: Psychodidae) main cutaneous leishmaniasis vectors, introduction of a new subgroup wSerg. Pathogens and global health. 2018;112(3):152-60.

62. Mostafavi E, Rastad H, Khalili M. Q Fever: An emerging public health concern in Iran. Asian Journal of Epidemiology. 2012;5(3):66.

63. Doosti A, Arshi A, Sadeghi M. Investigation of Coxiella burnetii in Iranian camels. Comparative Clinical Pathology. 2014;23(1):43-6.

64. Parhizgari N, Gouya MM, Mostafavi E. Emerging and re-emerging infectious diseases in Iran. Iranian journal of microbiology. 2017;9(3):122. 
65. Rahmdel S, Moezzi MS, Azimzadeh N, Hosseinzadeh S. PCR Detection of Coxiella Burnetii in Bovine Bulk Tank Milk Samples in Shiraz, Southern Iran. International Journal of Nutrition Sciences. 2018;3(4):198-201.

66. Traub R, Wisseman Jr CL. The ecology of chigger-borne rickettsiosis (scrub typhus). Journal of medical entomology. 1974;11(3):237-303.

67. Sakamoto JM, Azad AF. Propagation of arthropod-borne Rickettsia spp. in two mosquito cell lines. Applied and environmental microbiology. 2007;73(20):6637-43.

68. de Almeida F, Moura AS, Cardoso AF, Winter CE, Bijovsky AT, Suesdek L. Effects of Wolbachia on fitness of Culex quinquefasciatus (Diptera; Culicidae). Infection, Genetics and Evolution. 2011;11(8):2138-43.

69. Iturbe-Ormaetxe I, Walker T, O'Neill SL. Wolbachia and the biological control of mosquito-borne disease. EMBO reports. 2011;12(6):508-18.

70. Dieme C, Bechah Y, Socolovschi C, Audoly G, Berenger J-M, Faye O, et al. Transmission potential of Rickettsia felis infection by Anopheles gambiae Proceedings of the National Academy of Sciences. 2015;112(26):8088-93.

71. Maina AN, Klein TA, Kim H-C, Chong S-T, Yang Y, Mullins K, et al. Molecular characterization of novel mosquito-borne Rickettsia spp. from mosquitoes collected at the Demilitarized Zone of the Republic of Korea. PloS one. 2017;12(11):e0188327.

72. Jeffries CL, Lawrence GG, Golovko G, Kristan M, Orsborne J, Spence K, et al. Novel Wolbachia strains in Anopheles malaria vectors from sub-Saharan Africa. Wellcome open research. 2018;3.

73. Ramesh D, Muniaraj M, Samuel PP, Thenmozhi V, Venkatesh A, Nagaraj J, et al. Seasonal abundance \& role of predominant Japanese encephalitis vectors Culex tritaeniorhynchus \& gelidus Theobald in Cuddalore district, Tamil Nadu. The Indian journal of medical research. 2015;142(Suppl 1):S23.

\section{Figures}




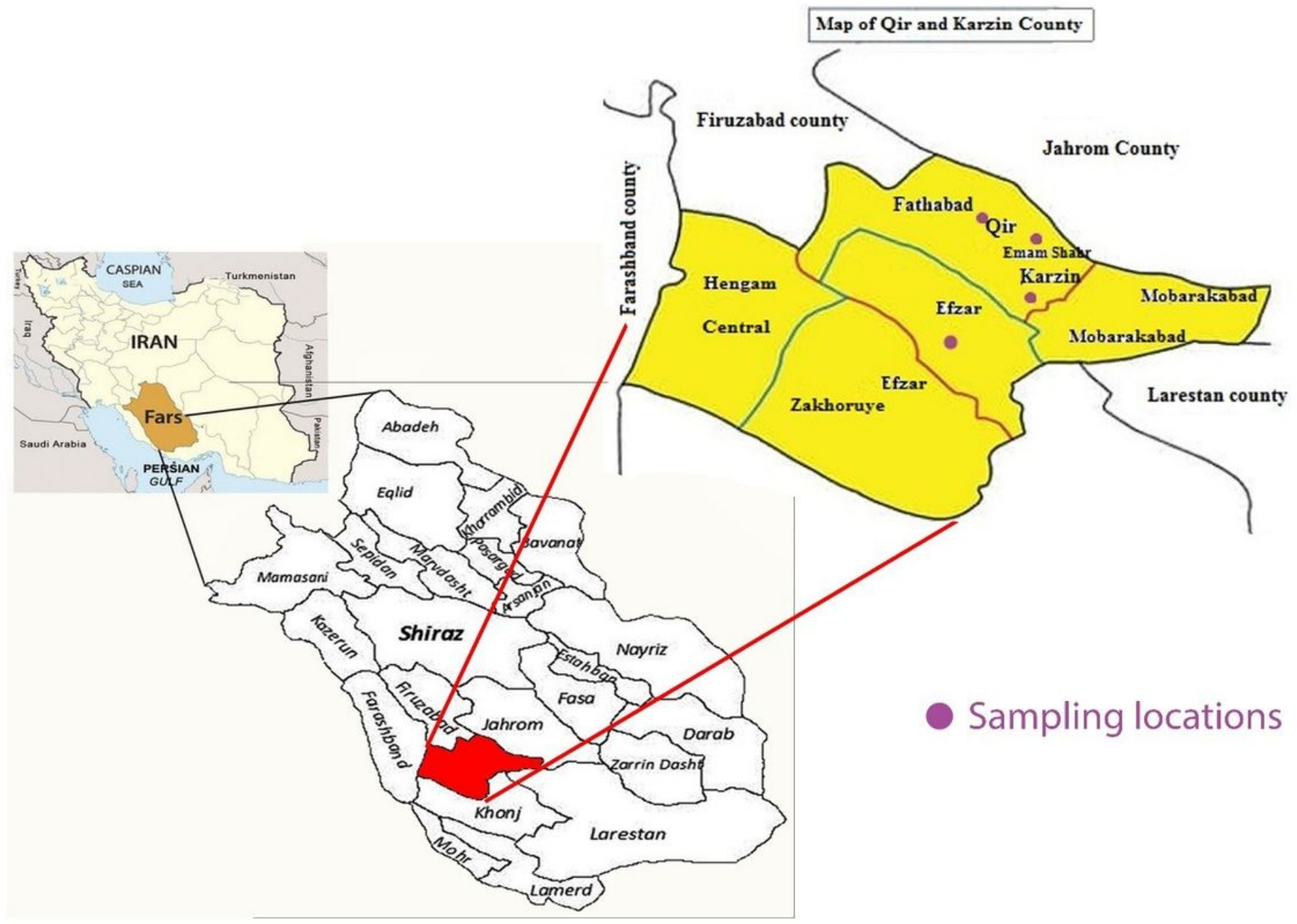

Figure 1

Map of Qir and Karzin County and sampling locations

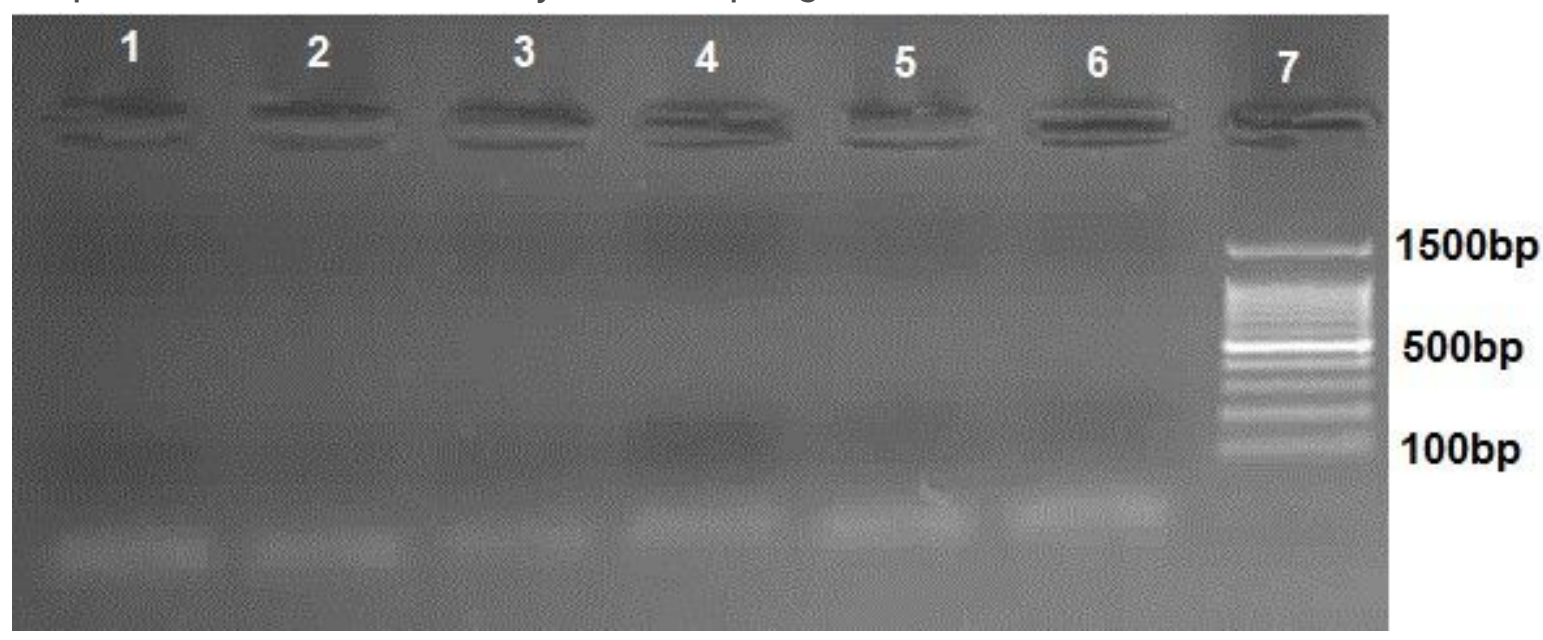

Figure 2

A gel scheme and the negative result of testing the possible contamination of mosquitoes with Rickettsia spp. and Coxiella burnetii (from left to right: 1: Negative control:; 2,3 and4:: examined samples in terms of 
gltA; 5 and 6: examined samples in terms of Coxiella burnetii), and 7: Ladder 100bp sinaclone Co.

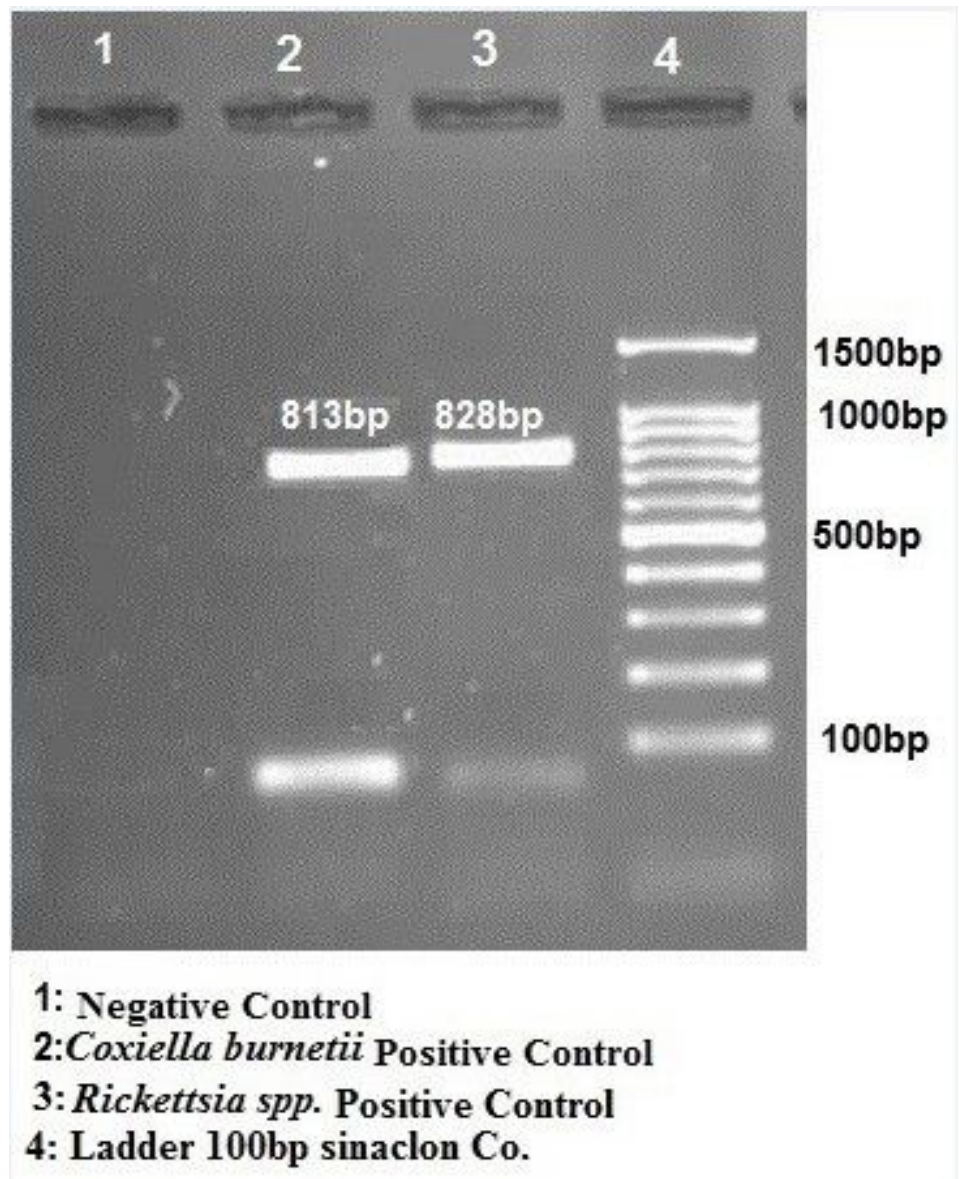

\section{Figure 3}

A gel scheme of positive control of Coxiella burnetii and Rickettsia spp. 